\title{
Editorial
}

\section{Special Issue on Pesticide Applications in Agricultural Systems}

\author{
Giuseppe Manetto*(D), Emanuele Cerruto (D), Domenico Longo (D) and Rita Papa (D) \\ Department of Agriculture, Food and Environment (Di3A), Section of Mechanics and Mechanization, \\ University of Catania, via Santa Sofia, 100, 95123 Catania, Italy; emanuele.cerruto@unict.it (E.C.); \\ domenico.longo@unict.it (D.L.); rita.papa@gmail.com (R.P.) \\ * Correspondence: giuseppe.manetto@unict.it; Tel.: +39-095-7147-515
}

Citation: Manetto, G.; Cerruto, E.; Longo, D.; Papa, R. Special Issue on Pesticide Applications in Agricultural Systems. Appl. Sci. 2021, 11, 3695. https://doi.org/10.3390/app11083695

Received: 22 March 2021

Accepted: 16 April 2021

Published: 20 April 2021

Publisher's Note: MDPI stays neutral with regard to jurisdictional claims in published maps and institutional affiliations.

Copyright: (c) 2021 by the authors. Licensee MDPI, Basel, Switzerland. This article is an open access article distributed under the terms and conditions of the Creative Commons Attribution (CC BY) license (https:/ / creativecommons.org/licenses/by/ $4.0 /)$.

\section{Introduction}

The European Directive 2009/128/EC on the Sustainable Use of Pesticides recognizes the use of Plant Protection Products (PPP) as having great impact on human health and the environment [1]. The directive imposes several obligations, among which are the following: to inform the general public of the overall impacts of the use of pesticides and end-users on their safe handling and storage, as well as on the disposal of the empty packaging, tank mixtures, and remnants; to promote research programs aimed at determining the impacts of pesticide use; to pay particular attention to avoiding the pollution of surface and groundwater, the aquatic environment being especially sensitive to pesticides; to prohibit aerial spraying of pesticides due to its potential to cause significant adverse impacts, in particular from spray drift; to set up systems training for distributors, advisors, and professional users of pesticides; and to provide for systems for regular technical inspection of pesticide application equipment already in use.

Given this framework and, however, taking into account the benefits of pesticides when used rationally and carefully in increasing crop yields, improving food safety, quality of life and longevity, energy use, and environmental degradation [2], researchers, chemical companies, and sprayer manufacturers operate to make PPP application more sustainable, making more selective active ingredients available and promoting alternative approaches such as organic farming $[3,4]$.

\section{Main Aspects Involved in Pesticide Application in Agriculture}

Effective and efficient application of PPP in agriculture is a very complex task involving a lot of aspects ranging from active substance properties (physical status, volatility, selectivity, persistency) to climatic conditions (wind speed, air temperature, and relative humidity), from target structure (canopy or ground, vegetative development, canopy arrangement) to equipment features (state of maintenance, air assistance, proper calibration), and from operator awareness (level of education, training, expertise in choosing the appropriate operating parameters) to the reference legislative framework (ISO standards, European Directives, national and local obligations).

All these aspects, and many others, have been studied by the scientific community and are well referenced in the literature, and some of them have been treated by the authors that contributed to this Special Issue (SI) on Pesticide Applications in Agricultural Systems.

When spraying liquid PPP, a key factor that affects most aspects of a phytosanitary treatment is the drop size spectrum, because an optimal droplet spectrum ensures the transfer of the required dose to the target; minimizes the off-target losses due to evaporation, drift, and run-off; and reduces worker's dermal and inhalation exposure. The first four papers in this Special Issue focus on the importance of drop size spectrum on pesticide applications.

The first article, authored by Longo et al., presents a laboratory low-cost test bench for testing agricultural spray nozzles [5]. The paper provides a comprehensive description of the test bench, its design, construction, advantages, and limitations during its functioning, 
as well as the results of some trials with an ATR80 orange hollow cone nozzle to test the functionality of the whole system. The measurement method is inspired by the ISO 5682-1 [6] and is based on the image analysis of droplets trapped inside a layer of silicone oil of suitable density and viscosity.

The second article in this Special Issue, authored by Grella et al., is strictly connected to the first one. It deals with the designing of two pneumatic spouts for vineyard applications capable of generating droplet size spectra in a wide range of options [7]. Through laboratory trials simulating a real sprayer, the paper assesses the influence of hose insertion position, liquid flow rate, and airflow speed on droplet size, homogeneity, and driftability. A proper combination of these parameters allows for varying the spray quality from very fine to coarse/very coarse, providing farmers with a wide range of options to match the drift-reducing EU policy requirements when using pneumatic sprayers and the treatment specifications for every spray application.

The third article in this Special Issue, authored by Ranjan et al., exploits the use of modified micro-emitters, usually used in greenhouse irrigation systems, in fixed agrochemical delivery systems composed of a network of micro-sprayers/nozzles distributed in an apple orchard, replacing conventional hollow cone nozzles [8]. Ranjan et al. found that all the usually assessed spray parameters, i.e., spray coverage, canopy deposition, spray uniformity, and ground and aerial spray losses, were all affected by droplet spectrum and worked better with the modified irrigation micro-emitters when compared to the hollow cone nozzles. In addition, the installation cost was greatly reduced.

The fourth article in this Special Issue, authored by Wang et al., evaluates the handler's exposure to pesticides from stretcher-type power sprayers in orchards [9]. Spray drop spectrum also plays a key role in operator dermal and inhalation exposure, together with the task being performed, target features, canopy structure, the amount of pesticide handled, the duration of the activity, the personal protective equipment used, the type of equipment used and its status, and others [10]. Wang et al. found that inhalation exposure was negligible compared with dermal exposure, and that hands were the most exposed body part. Their results can be used as a reference for the handler's safety in pesticide management and mechanical orchard management.

The fifth paper in this Special Issue, authored by Rhoades and Stoddard, deals with the environmental effects of pesticides on non-target organisms [11]. Specifically, the research highlights a relationship between the spray application of a broad-spectrum insecticide and its effects on the predator activity of spiders and mosquito populations after treatment. Even if the pesticide dose was not lethal for spiders, their predator activity was reduced, and the mosquito population rebounded quickly after spray application. The authors propose further studies to assess the significance of the temporal association between the loss-of-predator ecosystem function of spiders and the rapid population rebound of mosquitos, as well as the adoption of other mosquito control methods, such as bacterial larvicides capable of avoiding these potential problems.

The last paper, authored by Facchinetti et al., is an example of how artificial intelligence can be used in precision spraying to reduce the volume sprayed and, subsequently, decrease the environmental impact of pesticides [12]. In the paper, the authors present the design of a prototype "rover" capable of adjusting the spraying parameters according to the target features, which are detected in real time by means of a 3D camera. Compared to the commonly distributed mixture volume in greenhouse fresh-cut salads, the prototype was able to reduce the amount of product sprayed by up to $55 \%$, still assuring excellent crop coverage.

\section{Future Perspectives on Pesticide Application in Agriculture}

A continuous evolution is influencing spraying techniques to make pesticide application more sustainable; the monitoring of spray drift, using sensors to detect the target, the mapping of crop parameters, and developing variable rate sprayers are all aspects analyzed by researchers and sprayer manufacturers to implement sustainable precision farming 
systems. The availability of a huge amount of data coming from several sources (satellites, drones, ground) on all variables that can affect PPP distribution (climatic conditions, crop features, and the positioning and control of the sprayer) would result in the better targeted use of all available pest control measures. Therefore, as stated by the 2009/128/EC Directive, "it would contribute to a further reduction of the risks to human health and the environment and the dependency on the use of pesticides".

Funding: This research was carried out within the research project "Contributo della meccanica agraria e delle costruzioni rurali per il miglioramento della sostenibilità delle produzioni agricole, zoo-tecniche e agro-industriali. WP1: Impiego sostenibile di macchine irroratrici in serra e in pieno campo", financed inside the "Linea di intervento 2-dotazione ordinaria per attività istituzionali dei dipartimenti-2016-18-II annualità" of the University of Catania.

Acknowledgments: We are grateful to all authors for their contributions and making this Special Issue a success. Many thanks to all reviewers that provided responsible suggestions and comments. We would also like to express our gratitude to all members of the editorial team of Applied Sciences and especially to Christy Cui for their professional support.

Conflicts of Interest: The authors declare no conflict of interest.

\section{References}

1. European Union. Directive 2009/128/EC of the European Parliament and of the Council of 21 October 2009 establishing a framework for Community action to achieve the sustainable use of pesticides. Off. J. L 2009, 309, 71-86.

2. Cooper, J.; Dobson, H. The benefits of pesticides to mankind and the environment. Crop. Prot. 2007, 26, 1337-1348. [CrossRef]

3. Lamichhane, J.R. Pesticide use and risk reduction in European farming systems with IPM: An introduction to the special issue. Crop. Prot. 2017, 97, 1-6. [CrossRef]

4. Papa, R.; Manetto, G.; Cerruto, E.; Failla, S. Mechanical distribution of beneficial arthropods in greenhouse and open field: A review. J. Agric. Eng. 2018, 785, 81-91. [CrossRef]

5. Longo, D.; Manetto, G.; Papa, R.; Cerruto, E. Design and Construction of a Low-Cost Test Bench for Testing Agricultural Spray Nozzles. Appl. Sci. 2020, 10, 5221. [CrossRef]

6. ISO (International Organization for Standardization). ISO 5682-1, Equipment for Crop. Protection-Spraying Equipment-Part 1: Test. Methods for Sprayer Nozzles; ISO: Geneva, Switzerland, 2017. Available online: https://www.iso.org/standard/60053.html (accessed on 16 July 2020).

7. Grella, M.; Miranda-Fuentes, A.; Marucco, P.; Balsari, P.; Gioelli, F. Development of Drift-Reducing Spouts for Vineyard Pneumatic Sprayers: Measurement of Droplet Size Spectra Generated and Their Classification. Appl. Sci. 2020, 10, 7826. [CrossRef]

8. Ranjan, R.; Sinha, R.; Khot, L.; Hoheisel, G.; Grieshop, M.; Ledebuhr, M. Spatial Distribution of Spray from a Solid Set Canopy Delivery System in a High-Density Apple Orchard Retrofitted with Modified Emitters. Appl. Sci. 2021, 11, 709. [CrossRef]

9. Wang, Z.; Meng, Y.; Mei, X.; Ning, J.; Ma, X.; She, D. Assessment of Handler Exposure to Pesticides from Stretcher-Type Power Sprayers in Orchards. Appl. Sci. 2020, 10, 8684. [CrossRef]

10. Cerruto, E.; Manetto, G.; Santoro, F.; Pascuzzi, S. Operator dermal exposure to pesticides in tomato and strawberry greenhouses from hand-held sprayers. Sustainability 2018, 10, 2273. [CrossRef]

11. Rhoades, S.; Stoddard, P. Nonlethal Effects of Pesticides on Web-Building Spiders Might Account for Rapid Mosquito Population Rebound after Spray Application. Appl. Sci. 2021, 11, 1360. [CrossRef]

12. Facchinetti, D.; Santoro, S.; Galli, L.; Fontana, G.; Fedeli, L.; Parisi, S.; Bonacchi, L.; Šušnjar, S.; Salvai, F.; Coppola, G.; et al. Reduction of Pesticide Use in Fresh-Cut Salad Production through Artificial Intelligence. Appl. Sci. 2021, 11, 1992. [CrossRef] 